\title{
A Substantive Revision to Firth's Ideal Observer Theory
}

\begin{abstract}
This paper examines Ideal Observer Theory and uses criticisms of it to lay the foundation for a revised theory first suggested by Jonathan Harrison called Ideal Moral Reaction Theory. Harrison's Ideal Moral Reaction Theory stipulates that the being producing an ideal moral reaction be dispassionate. This paper argues for the opposite: an Ideal Moral Reaction must be performed by a passionate being because it provides motivation for action and places ethical decision-making within human grasp.
\end{abstract}

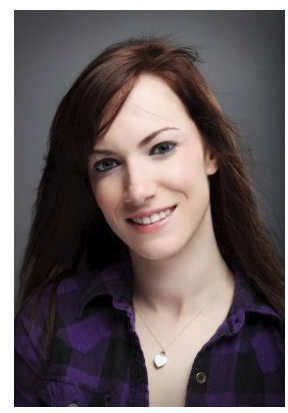

Nancy Rankin is a philosophy major and religious studies minor at Austin Peay State University in Clarksville, Tennessee. Her philosophical interests mainly center around ethical theory and the philosophy of religion. In her spare time, she enjoys reading and plans to become a fiction author sometime in the near future.

I n an article titled "Ethical Absolutism and the Ideal Observer," Roderick Firth advocates a theory that has come to be known as the Ideal Observer Theory. Ideal Observer Theory asserts that right and wrong are determined by an ideal observer's reaction to a given act. That is, any act $X$ is morally permissible if an ideal observer would approve of $\mathrm{X}$; conversely, any act $\mathrm{Y}$ is morally blameworthy if an ideal observer would disapprove of $\mathrm{Y}$.

In this paper, I examine several of the strengths and weaknesses of Ideal Observer Theory and explain how together, these strengths and weaknesses lay the foundation for a revised version of Ideal Observer Theory which can be termed Ideal Moral Reaction Theory. Although this theory was first suggested by Jonathan Harrison, I make a substantive revision to his conception of the theory when I argue that an individual attempting an ideal moral reaction would be a passionate being, rather than the dispassionate one Harrison suggests. This, I argue, places ethical decision-making within the grasp of human beings and thus makes it a pragmatic concept.

Firth expounds upon several characteristics of an ideal observer. An ideal observer is omniscient with respect to non-ethical facts, omnipercipient, disinterested, dispassionate, consistent, and in 
other respects, normal. ${ }^{1}$ Some of these characteristics require further elucidation. The requirement for omniscience is a weighty one, as it strongly limits who (or what) can act as an ideal observer. Firth argues, however, that "to say that an ideal observer is omniscient is to insure that no limits are put on the kinds or the quality of factual information which are available to influence his ethically significant reactions." 2 That is, according to Firth, an ideal observer must be omniscient so as to avoid being mistaken when making ethical decisions. All relevant facts must be taken into consideration. In order to ensure that all relevant facts are, in fact, taken into consideration, Firth prescribes omniscience as a necessary characteristic of an ideal observer.

Firth's requirement for omnipercipience also greatly limits ideal observers, as an omnipercipient being is one that "must be able... simultaneously to visualize all actual facts, and the consequences of all possible acts in any given situation." 3 That is, as Firth suggests, the ideal observer must have "extraordinary powers of imagination." 4

Further, Firth argues that the ideal observer must be impartial and that impartiality requires the ideal observer to be both disinterested and dispassionate. He argues that a simple lack of interest in a given situation is not enough to ensure impartiality, thus arguing the ideal observer must also lack the passions that so often infect the thoughts and actions of most human beings.
The ideal observer must also be consistent, meaning that he or she would not react differently to two situations exhibiting the same characteristics. That is, if $\mathrm{A}=\mathrm{B}$, the ideal observer would not disapprove of A and simultaneously approve of B.

Finally, Firth asserts that the ideal observer must be, in all other respects, a normal being. By normal, Firth simply means this individual cannot be suffering from a brain tumor or psychological disorder that may skew his or her judgment on ethical matters. All other aspects of this being must be simply normal.

In his article "The Definition of an 'Ideal Observer' Theory in Ethics," Richard Brandt discusses seven reasons why this theory should be considered further. Two of these reasons have implications for the revised Ideal Observer Theory I will later suggest, so it is to these I will now turn. First, Brandt writes that this theory, "explains why our feelings and attitudes - and especially our sympathies - are (and properly are) engaged in ethical reflection, and why moral philosophers have thought that moral experience is distinctively a union of cognition and emotion." ${ }^{5}$ That is, this theory explains why we incorporate our feelings and attitudes into ethical decision-making, as this is also what an ideal observer does when making ethical decisions.

Second, Ideal Observer Theory, "explains why we value the advice of knowledgeable, impartial, and consistent persons at times of

1. Roderick Firth, "Ethical Absolutism and the Ideal Observer," Philosophy and Phenomenological Research, Vol. 12, No. 3 (1952): 333344.

2. Firth, "Ethical Absolutism," 334.

3. Ibid: 335 .

4. Ibid.

5. Richard Brandt, "The Definition of an 'Ideal Observer' Theory in Ethics," Philosophy and Phenomenological Research, Vol. 15, No. 3 (1955): 407. 
moral decision, and why we reject previous moral opinions of our own which we think reflect self-interest, inconsistency, or lack of information." 6 That is, most individuals value such things as knowledge, impartiality, and consistency in ethical-decision making; conversely, they find lack of knowledge, selfinterest, or lack of consistency as characteristics antithetical to objective ethical reflection. Hence, this theory is consistent with what most people pragmatically value in ethical reflection.

Although this theory has its strengths, Ideal Observer Theory has been scrutinized in a variety of ways. In the following pages, I will address three of the problems recognized by philosophers: the problem of omniscience and omnipercipience, the problem of a dispassionate observer, and a problem that I have termed the problem of the lucky guess.

Richard Brandt argues that the characteristics of omniscience and omnipercipience, as deemed necessary by Firth, "eat away at the human characteristics of the ideal observer." ${ }^{7}$ Brandt suggests that no human being can successfully achieve ideal observer status if omniscience and omnipercipience are required. This status must be delegated only to a God-like or superhuman being. Consequently, Ideal Observer Theory can do little to help us in making important ethical decisions.

"Relativising the Ideal Observer Theory," an article by Charles Taliaferro, suggests that omniscience (and, it can be assumed, omnipercipience as well) is not metaphysically impossible when he writes, "could not God simply create a human who knew the truth value of all propositions?" 8 That is, it seems metaphysically possible for God to create an omniscient human. Since this is possible, he argues, omniscience and omnipercipience do not present problems for Ideal Observer Theory. This solution, however, is inadequate.

In addition to assuming the existence of God, an assumption not necessary in Ideal Observer Theory, the argument seems to beg the question. That is, given that the problem exists because no known human being exhibits the characteristics of omniscience or omnipercipience, creating a solution by saying that one could be created does very little to help us in making practical ethical decisions.

Given that ethics should be concerned with practical elements rather than nearly impossible metaphysical entities, it seems the possibility of the creation of an omniscient and omnipercipient human being does little to actually help us. Since a normal human being cannot achieve omniscience or omnipercipience, it seems inconsequential to suggest that this could occur. Furthermore, common intuition tells us that no normal human being can achieve this status; thus, additional justification for this claim seems unnecessary. It seems the burden of proof is on the individual who claims there are human beings who exhibit these qualities, rather than the individual who does not.

Instead of arguing that omniscience and omnipercipience are necessary, Brandt suggests an alternative:

\footnotetext{
6. Brandt, "Definition," 407.

7. Ibid: 409.

8. Charles Taliaferro, "Relativising the Ideal Observer Theory," Philosophy and Phenomenological Research, Vol. 49, No. 1 (1988): 125.
} 
What a person needs to be vividly conscious of, in judging or reacting to an ethical situation, is simply all those facts vivid awareness of which would make a difference to his ethical reaction to this case if (to use Firth's other qualifications) he were a disinterested, dispassionate but otherwise normal person. ${ }^{9}$

Brandt is suggesting that an ideal observer need not be omniscient or omnipercipient, but rather simply exhibit these other Firthian qualities in order to be classified as an ideal observer. This suggestion, however, is also inadequate because it presents a problem which can be called the problem of relevant facts.

The problem can be formulated as follows: if a being is neither omniscient nor omnipercipient, he cannot be sure he is "vividly aware" of all the relevant facts of an ethical situation because his knowledge is limited. He cannot know which facts would make a difference to his ethical reaction unless he is aware of all other nonethical facts. An individual needs omniscience and omnipercipience in order to ensure that all relevant facts are considered. Without knowing all facts, an ethical decision-maker cannot have this assurance.

Given the problem of omniscience and omnipercipience and the problem of relevant facts, we have reached an impasse with regard to Ideal Observer Theory. On the one hand, omniscience and omnipercipience limit an ideal observer to a God-like or superhuman being, thus making the theory impractical in ethical reflection. On the other hand, taking away the omniscience and omnipercipience requirements and instead incorporating the ethically-relevant solution regarding knowledge of facts, exhibits circularity because an individual cannot know he or she has all ethically relevant facts without in fact knowing all facts. It is for this reason that the problem of omniscience and omnipercipience is such a serious problem with no solution yet to solve it.

In the article, "Some Comments on Professor Firth's Ideal Observer Theory," Jonathan Harrison raises the problem of a dispassionate observer when he writes, "a being who had no passions... would have no moral reactions." ${ }^{10}$ A being that had no emotions or sympathies regarding an ethical dilemma would consequently hold no moral reaction to such a dilemma. What, then, would be the cause of this dispassionate observer's reactions? If an ideal observer were completely dispassionate, he or she would not care enough to make a decision regarding an ethical dilemma.

Harrison further argues if, "you allow an ideal observer to have passions, you are faced with the problem of specifying which of his passions may affect his moral reactions, and which may not."11 What criteria do we have to determine which passions should be accepted as influential in ethical decision-making and which should not?

Thus, it seems we have reached another impasse in regards to Ideal Observer Theory. Arguing that an ideal observer should be dispassionate is problematic because it allows no room for right decision-making, as a dispassionate

\footnotetext{
9. Brandt, "Definition," 410.

10. Jonathan Harrison, "Some Comments on Professor Firth's Ideal Observer Theory," Philosophy and Phenomenological Research, Vol. 17, No. 2 (1956): 260.

11. Harrison, "Comments," 260.
} 
observer would fail to want to make a decision. However, allowing an ideal observer to retain passions is problematic because one must then determine which passions can be allowed in ethical reflection and which would impede objective decision-making.

I have developed a rudimentary solution to the problem of a dispassionate observer, as will be discussed shortly. The problem I have termed "the problem of the lucky guess" is further proof that Ideal Observer Theory needs substantive revisions or additions. Although Firth describes in great detail the characteristics that constitute an ideal observer, he does little to suggest how a non-ideal observer could actually make ethical decisions. The problem of the lucky guess is a problem of practicality. An example can best explain this problem.

Take Ethan, a calm, conscientious, rational decision-maker who has attempted to gain all of the relevant facts of a situation in which ethical reflection is necessary. Now consider Eric, an erratic, irrational, hasty decision-maker who has little knowledge of the facts of a situation. Since Ideal Observer Theory depends only on the reaction of an ideal observer, Eric could just as easily possess the ideal observer's response to an ethical decision as Ethan, despite the fact that Ethan exhibits more rationality and conscientiousness regarding ethical decisionmaking.

An epistemic "lucky guess" on the ethical implications of a given action could be correct, even though the lucky ethical decisionmaker failed to take into consideration those characteristics we deem worthy of consideration, i.e. knowledge of the situation, rationality, consistency, etc. Ultimately, the problem of the lucky guess illustrates that Firthian IdealObserver Theory gives us no method for determining right action and, consequently, places the epistemic lucky guess on the same level as a guess based in reason and rationality.

What do the problems of omniscience and omnipercipience, the dispassionate observer, and the lucky guess mean for Ideal Observer Theory? As I have suggested, these problems indicate that Firth's theory requires substantive revision. The solution I offer to these problems - and the revision to Ideal Observer Theory I suggest was first considered by Jonathan Harrison when he wrote that individuals should consider ideal moral reactions as characteristic of correct ethical decisions, as opposed to the concept of an ideal observer. He writes:

\footnotetext{
You may simply define 'ideal moral reaction' as one which is disinterested, dispassionate, etc. There is no need for the person who has the ideal reaction to $\mathrm{A}$ to be disinterested, dispassionate, and so on, on every occasion on which he experiences a moral reaction. Hence observers who are far from ideal may have ideal moral reactions. Hence the fact that there are no ideal observers would not prevent there being ideal moral reactions, and so statements about 'all ideal reactions' need not be statements about null classes, even if statements about ideal observers are. ${ }^{12}$
}

Harrison is suggesting that we consider ideal moral reactions to situations, which he argues can be defined as reactions that are disinterested, dispassionate, etc. The point Harrison makes is clear: when we talk of ideal observers, we are not talking about anything that actually exists - that is, unless God or superhuman beings exist, which,

12. Harrison, "Comments," 257. 
as previously discussed, need not be considered. Ideal moral reactions, on the other hand, could exist. It is to this concept that I will now turn in an attempt to expound upon Harrison's suggestion.

Harrison argues that an ideal moral reaction would consist of the following requirements:

(a) It would not be altered by any increase in knowledge or true opinion by the observer whose reaction it is, whether this increase in knowledge or true opinion takes the form of the addition of any one piece of information, or any possible combination of pieces of information.

(b) To make sure that the class of ideal reactions is not null, I cannot say that the observer who has the reaction has no false beliefs. Instead I shall stipulate that he has no false beliefs which would be such that the removal of any, either severally, or in any combination, alters his reaction. ${ }^{13}$

With (a) and (b), Harrison is attempting to solve the impasse between omniscience and omnipercipience and relevant facts. Rather than having an ethical decision-maker omniscient and omnipercipient, Harrison first suggests that the decision-maker's ethical choice must not be altered by any further information. This avoids the problem that no being can be omniscient or omnipercipient, yet fails to encounter the problem of relevant facts because it does not suggest that one must know what knowledge is relevant or irrelevant. Instead, when making an ethical decision the individual must attempt to gain as much knowledge as possible about the situation - enough to reasonably ensure him or her that the decision would not be altered by further evidence.
Although an individual can never be epistemically certain he or she has attained that level of knowledge, it gives him or her an incentive to seek the facts, and to do so to the extent that his or her knowledge gives an answer beyond a reasonable doubt.

Harrison is further by-passing these problems because he accepts that individuals may have false beliefs, which is a fact of human existence, yet something Firth's ideal observer could not possess. This fact simply provides individuals making ethical decisions a further incentive to seek as much knowledge as possible about the situation before making any decision.

Harrison, however, argues an individual making an ethical decision must be disinterested and dispassionate; that is, he argues for the same impartiality that Firth does for his ideal observer. Agreeing with Taliaferro and his suggestion that a dispassionate observer would not make any decision at all, I argue that an individual seeking to attain this type of ideal moral reaction to an ethical situation would, in fact, be allowed passions, as it is something that most human beings have whether they are aware of it or not.

For instance, most human beings would cringe at the thought of children being tortured during the Nazi Holocaust. This reaction is passionate, yet does not seem to be an incorrect reaction. Indeed, it seems some level of passion is necessary to make ethical decisions - what matters is that an individual has the right level of passion, a fact which has already been shown to be problematic. How, then, are we to determine what the right level of passion should be?

I argue it is simply human for an individual to feel passions, and since we are talking about

13. Ibid., 258. 
humans, rather than some metaphysical ideal observer, this is okay. In fact, given that ethics is entirely about human beings, it seems unwise to develop a theory to the contrary, as the dispassionate observer does. With regard to which passions should be admitted and which should be rejected, I suggest that we simply require that these passions do not cloud the judgment of the ethical decision maker to the extent that he or she would ignore all other facts of the situation at hand. As long as the passions do not hold more sway than a substantial amount of evidence towards the contrary viewpoint, those passions should be admitted in ethical reflection.

How does the concept of an ideal moral reaction, as opposed to an ideal observer, fare with the problem of the lucky guess? As we can stipulate what it takes to have an ideal moral reaction, we can suggest what steps an individual should take in order to achieve an ideal moral reaction. Consequently, the concept of a lucky guess is no longer as problematic - Ethan, our rational, consistent, knowledgeable decisionmaker, would indeed be closer to making an ideal moral judgment than Eric, the erratic, irrational decision maker who could have fared just as well under Ideal Observer Theory.

My contribution to Ideal Moral Reaction Theory is simple: remove the requirement that the reaction be dispassionate, as this requirement is nonsensical because passions are necessary for any reaction to occur. Ultimately, my conception of an ideal moral reaction is one in which an individual is disinterested, rational, has sufficient knowledge of the situation at hand, and would be consistent if the given situation were to arise again. This is superior to the one defended by Harrison because it takes into account human passions that exist whether an individual claims they do or not.

My theory also accounts for the problems of omniscience and omnipercipience by not requiring them, yet accounts for the problem of relevant facts by arguing that an individual must not be persuaded to change his or her opinion by the addition or removal of facts. Further, it does not succumb to the problem of the lucky guess because it pragmatically offers a means for an individual to work towards making an ideal moral decision. This theory also maintains the strengths of ideal observer theory mentioned earlier: it still explains the ways in which our attitudes and passions influence our thinking and explains why we regard individuals who are rational, consistent, and level-headed as better ethical decision-makers.

In this paper, I have reviewed the Ideal Observer Theory provided by Roderick Firth and examined some of the strengths and weaknesses of this theory. I have further argued that, in order to avoid the problems presented by Ideal Observer Theory, we should instead adopt a theory of ideal moral reactions, as first introduced by Jonathan Harrison. In adopting his theory, I have altered the concept of an ideal moral reaction to be one that is passionate, as passions must exist for a reaction to occur at all. The argument is strengthened because it makes ideal moral reactions possible for humans to actually attain. 